\title{
TRATAMENTO DO ÓLEO DE FRITURA COM FIBRA DE COCO PARA POSTERIOR OBTENÇÃO DE BIOCOMBUSTIIVEIS.
}

\section{T. CALIMAN CATELAN ${ }^{1}$, F. BRITO DOS SANTOS ${ }^{1}$, A. N. FURLAN MENDES ${ }^{2}$ e S. M. SANTANA ROCHA ${ }^{3}$}

${ }^{1}$ Universidade Federal do Espírito Santo, Departamento de Engenharias e Tecnologia

${ }^{2}$ Universidade Federal do Espírito Santo, Departamento de Ciências Naturais

${ }^{3}$ Universidade Federal do Espírito Santo, Departamento de Educação e Ciências Humanas

E-mail para contato: thais_cali@hotmail.com

RESUMO - A preocupação com o meio ambiente e a necessidade de redução dos níveis de poluição são fatores que têm contribuído para a busca de combustíveis alternativos aos derivados de petróleo. Dentre as alternativas encontradas, o biodiesel obtido a partir do óleo de fritura pode ser uma alternativa técnica viável e já foi comprovada por vários estudos. Com isso, a reciclagem do óleo de fritura vem ganhando espaço cada vez maior, já que, o aproveitamento deste resíduo evita a degradação e diminui a poluição ambiental. No entanto, a principal dificuldade na utilização do óleo de fritura para a produção do biodiesel é o alto índice de acidez que este apresenta devido à grande quantidade de ácidos graxos liberados durante as quebras das cadeias lipídicas do óleo quando este é submetido a elevadas temperaturas. Por essa razão, o óleo de fritura deve ser tratado antes de ser utilizado na produção de biodiesel. Este trabalho teve como objetivo tratar o óleo residual de fritura utilizando a fibra de coco como material adsorvente para a redução da cor e do teor de acidez, visando a sua reutilização para a produção de biodiesel através da reação de transesterificação básica. Os resultados obtidos até o momento mostram que a fibra de coco é eficiente para redução do índice de acidez do óleo de fritura.

\section{INTRODUÇÃO}

O desenvolvimento de tecnologias que permitam utilizar fontes renováveis de energia tem sido motivado pela grande demanda dos recursos energéticos pelos sistemas de produção (Fukuda et al, 2001; Antolin et al, 2002).

As características que melhor representam as vantagens dos biocombustíveis sobre os de origem fóssil dizem respeito à ausência de enxofre e de compostos aromáticos, alto número de cetano, teor médio de oxigênio, maior ponto de fulgor, menor emissão de partículas ( $\mathrm{HC}, \mathrm{CO}$ e $\mathrm{CO}_{2}$ ), baixa toxicidade, além de ser biodegradável (Ferrari et al., 2005).

O biodiesel é considerado uma mistura de monoésteres alquílicos de ácidos graxos (ésteres graxos) que podem ser obtidos por esterificação de ácidos graxos ou por transesterificação de óleos e gorduras, compostos em grande parte de triacilglicerídeos (Meher et al., 2006). 
A principal dificuldade de utilização do óleo de fritura para a produção do biodiesel é o alto índice de acidez apresentado pelo óleo residual, que ocorre devido à grande quantidade de ácidos graxos liberados durante as quebras da cadeia lipídica do óleo quando este é aquecido a aproximadamente $180{ }^{\circ} \mathrm{C}$ (Zambelli, 2009; Choe e Min, 2007). Os ácidos graxos livres presentes reduzem a eficiência da conversão do óleo em biodiesel e, quando em contato com catalisador básico, pode induzir à reação de saponificação do óleo, transformando-o em sabão (Leite, 2008). Por essa razão, o óleo de fritura deve ser tratado previamente antes de ser utilizado na produção de biodiesel (Zhang et al., 2003).

Existem diferentes maneiras de reduzir a coloração e a acidez do óleo de fritura. Dentre elas destacam-se o craqueamento térmico para a redução da acidez (Botton et al., 2012) e o uso de adsorventes para a redução tanto da coloração como da acidez (Costa Neto e Freitas, 1996; Tose e Soares, 2011). Segundo Zhang e colaboradores, o pré-tratamento do óleo de fritura é eficiente, porém gera aumento do custo final do combustível quando comparado à utilização de óleos não residuais. Para reduzir o custo deste tratamento Zhang e colaboradores sugeriram o uso de resíduos naturais como adsorventes (Zhang et al., 2003).

A adsorção é um processo de separação no qual um ou mais componentes de uma mistura fluida (líquida ou gasosa) são adsorvidos na superfície de um material adsorvente sólido, por meio da operação unitária de transferência de massa (McCabe et al., 1993). O processo pode ser classificado como adsorção química ou adsorção física. $\mathrm{Na}$ adsorção química os componentes unem-se a superfície do adsorvente por meio da formação de ligações químicas. Já na adsorção física ocorrem interações de van der Waals, onde os componentes da mistura fluida são retidos junto à superfície do adsorvente por certo tempo (Atkins, 1999).

O presente trabalho teve como objetivo reduzir a coloração e a acidez do óleo residual de fritura utilizando a fibra de coco como material adsorvente e verificar a eficiência da adsorção da fibra de coco in natura e alcalinizada.

\section{MATERIAIS E MÉTODOS}

As atividades experimentais deste trabalho foram desenvolvidas nos laboratórios de Pesquisa do Centro Universitário Norte do Espírito Santo (CEUNES/UFES). O óleo de fritura foi obtido por doação de estabelecimentos comerciais de São Mateus/ES e a fibra de coco foi obtida através de doação da empresa D Martins Coco Verde, localizada em São Mateus/ES.

Primeiramente, o óleo de fritura passou por um processo de filtração para eliminar possíveis resíduos de alimentos, posterior secagem com sulfato de sódio e filtrado novamente para retirar o agente secante. Este material foi armazenado em frasco âmbar e a baixas temperaturas para evitar possíveis alterações no material.

A fibra obtida foi separada, lavada 10 vezes com água corrente, uma vez com água destilada e seca em estufa à $100^{\circ} \mathrm{C}$ até massa constante. A amostra foi triturada primeiramente através do moinho de facas e depois pelo moinho de bolas. Em seguida, o material triturado passou por um conjunto de peneiras de 10, 14, 20, 24 e 28 mesh, pois os testes de adsorção foram realizados em diferentes granulometrias da fibra. 
Após o tratamento do óleo e da fibra, os testes de adsorção foram realizados em duplicata, inicialmente, foram realizados com a fibra de coco na forma in natura, escolhida da maior granulação obtida nas peneiras que foi a peneira do topo no mesh 10, pois foi onde se obteve maior quantidade de fibra, para avaliar tempo de contato e porcentagem mássica. Primeiramente foram testadas em duplicata as porcentagens em massa de $0,5 \%, 1,0 \%, 1,5 \%$, $2,0 \%$ de adsorvente utilizando-se $50 \mathrm{~g}$ de óleo de fritura bruto. Os testes foram realizados a temperatura ambiente, sob agitação magnética e no tempo de 60 minutos.

Ao término dos testes o óleo bruto e as amostras obtidas foram analisadas pelo índice de acidez e índice de peróxido para posteriores comparações. O índice de acidez do óleo de fritura foi determinado de acordo com a Norma Cd 3d-63 para determinar a quantidade de ácidos graxos livres presentes e o índice de peróxido foi determinado de acordo com o método oficial Cd 8b-90 para determinar a quantidade de peróxidos liberados na oxidação do óleo durante o processo de fritura conforme descrito por Vargas(2013).

A porcentagem mássica com maior redução do índice de acidez foi utilizada para se determinar o tempo ótimo de adsorção. Dessa maneira, além do tempo de 60 minutos, realizaram-se também testes de adsorção com 30, 90 e 120 minutos. Após determinada as melhores condições experimentais de relação mássica e tempo, iniciou-se os testes com diferentes granulometrias, obtidas nas peneiras, da fibra alcalina, calcinada e também com a fibra in natura.

\section{RESULTADOS E DISCUSSÕES}

Foram realizadas três tipos de análises para acompanhar a eficácia do processo de adsorção, são elas, índice de acidez, índice de peróxido e o grau de clarificação.

No primeiro teste, em que foram analisadas as proporções mássicas de fibra em relação ao óleo em um tempo de 60 minutos, através dos cálculos dos índices de acidez (IA) e índice de peróxido (IP), a proporção em que se obtiveram os melhores resultados foi a de $0,5 \%$ de fibra, como apresentado na Tabela 1. Esta amostra obteve uma redução significativa quando comparado com as outras amostras. Por isso, esta relação mássica foi escolhida para a continuação dos testes de tempo de contato entre a fibra e o óleo de fritura. A acidez teve forte influência na decisão, pois uma grande quantidade de ácidos graxos liberados reduzem a eficiência da conversão do óleo em biodiesel e, quando em contato com catalisador básico, pode induzir à reação de saponificação do óleo, transformando-o em sabão (Leite, 2008).

Tabela 1. Resultados dos Índices de acidez (IA) e índice de peróxido (IP) do óleo sem e com tratamento com a fibra de coco. 


\begin{tabular}{|c|c|c|}
\hline $\begin{array}{llll}\text { Congresso Brasileiro de Engenharra } \\
\text { Quimica em Iniciação Científica }\end{array}$ & XI Cong & $\begin{array}{l}\text { rasileiro de Engenharia } \\
\text { em Iniciação Científica } \\
\text { Unicamp - Campinas - SP } \\
19 \text { a } 22 \text { de julho de } 2015\end{array}$ \\
\hline Amostra & IA $(\mathrm{mg} \mathrm{KOH} / \mathrm{g})$ & IP (meq O2/Kg) \\
\hline Óleo bruto & 0,1032 & $16,5287 \pm 0,61$ \\
\hline Óleo tratado com $0,5 \%$ de fibra & 0,0990 & $13,1064 \pm 0,80$ \\
\hline Óleo tratado com $1,0 \%$ de fibra & 0,1012 & $12,8309 \pm 1,30$ \\
\hline Óleo tratado com $1,5 \%$ de fibra & 0,1075 & $10,5265 \pm 0,45$ \\
\hline Óleo tratado com $2,0 \%$ de fibra & 0,1066 & $12,1188 \pm 0,50$ \\
\hline
\end{tabular}

O desvio do teste de acidez foi desconsiderado, já que não houveram variações significativas nas repetições das amostras.

Analisando-se a Tabela 1, observa-se que ocorreu uma redução do IP nos óleos tratados, porém o óleo de fritura utilizado no trabalho está fora dos padrões estabelecidos pela ANVISA, pois apresentou alta oxidação, visto que os resultados foram superiores a 10 meq $\mathrm{O}_{2} / \mathrm{kg}$. No entanto, observou-se que mesmo não estando dentro dos padrões estipulados, o processo de adsorção foi eficiente para redução dos índices de peróxido do óleo de fritura.

Com isto, para os testes de adsorção variando-se o tempo, a porcentagem mássica utilizada foi de $0,5 \%$. Os resultados obtidos de IA e IP estão apresentados na Tabela 2:

Tabela 2. Resultados dos testes de adsorção variando-se o tempo de contato com o óleo.

\begin{tabular}{ccc}
\hline Tempo & IA $(\mathrm{mg} \mathrm{KOH} / \mathrm{g})$ & $\mathrm{IP}(\mathrm{meq} \mathrm{O} / \mathrm{Kg})$ \\
\hline 0 minutos & 0,1032 & $16,5287 \pm 0,61$ \\
\hline 30 minutos & 0,0907 & $14,7938 \pm 0,87$ \\
\hline 60 minutos & 0,0991 & $13,1064 \pm 0,80$ \\
\hline 90 minutos & 0,1100 & $15,3821 \pm 0,98$ \\
\hline 120 minutos & 0,1235 & $15,3774 \pm 0,97$ \\
\hline
\end{tabular}

Assim, da mesma maneira que foi escolhida a porcentagem em massa de adsorção, escolheu-se o tempo de contato de 30 minutos devido a maior diminuição do IA.

Analisando os resultados obtidos na tabela 1 pode-se observar que nas porcentagens mássicas de $1,0 \%, 1,5 \%$ e $2,0 \%$ ocorreu um aumento da acidez quando comparadas com a acidez do óleo bruto. Na tabela 2 foi observado o mesmo comportamento para os tempos de 60, 90 e 120 minutos. Dessa forma, não foram encontradas justificativas literárias significativas para esse comportamento, porém serão realizados testes para que seja observado esse comportamento.

Os resultados do tratamento do óleo com a fibra de coco de acordo com as granulações são apresentados na tabela 3 . 
Tabela 3. Resultados dos testes de adsorção variando-se as granulações da fibra de coco.

\begin{tabular}{ccc}
\hline Amostra & IA $(\mathrm{mg} \mathrm{KOH} / \mathrm{g})$ & $\mathrm{IP}\left(\mathrm{meq} \mathrm{O}_{2} / \mathrm{Kg}\right)$ \\
\hline Óleo Bruto & 0,1032 & $16,5287 \pm 0,6$ \\
\hline Mesh 10 & 0,0907 & $14,7938 \pm 0,9$ \\
\hline Mesh $-14+20$ & 0,1078 & $15,7717 \pm 0,2$ \\
\hline Mesh $-20+24$ & 0,1039 & $15,2736 \pm 0,4$ \\
\hline Mesh $-24+28$ & 0,1138 & $15,3751 \pm 0,9$ \\
\hline Fundo & 0,1088 & $15,3840 \pm 0,8$ \\
\hline
\end{tabular}

As fibras que ficaram retidas nas peneiras $-10+14$ não houveram quantidades significativas para realizar os testes, por isso não foram apresentados resultados para essa granulação. Os testes iniciais foram realizados com as fibras do Mesh 10.

Como apresentado na Tabela 3, a granulação que apresentou o resultado mais significativo foi o que já estava sendo utilizado, o qual era o Mesh 10, com um menor índice de acidez. Assim como na tabela 1 e 2 os mesh $-14+20,-20+24,-24+28$ e o fundo apresentaram índice de acidez maior do que o do óleo bruto.

As análises para determinação do grau de clarificação, bem como os testes de adsorção com diferentes granulometrias com a fibra in natura e os testes com a fibra de coco tratada estão em andamento.

\section{CONCLUSÃO}

Muitas pesquisas estão sendo realizadas para a utilização de resíduos como materiais adsorventes, os chamados bioadsorventes. A grande disponibilidade e o baixo custo desses resíduos, tanto agrícolas como industriais, têm despertado interesse quanto ao seu melhor aproveitamento, reduzindo assim o seu descarte na natureza.

Devido às propriedades adsorventes da fibra de coco, os resultados preliminares mostraram-se pouco significativos, porém apresentaram uma redução da acidez do óleo de fritura após o tratamento com a fibra, diminuindo o seu índice de acidez. Embora os resultados obtidos até o momento não sejam os ideais para se alcançar os valores de índice de acidez para que os óleos de frituras possam ser utilizados na produção do biodiesel, testes de adsorção estão em andamento visando encontrar as melhores condições experimentais que possam enquadrar o óleo de fritura dentro dos parâmetros estabelecidos pela Agência Nacional do Petróleo (ANP).

\section{REFERÊNCIAS BIBLIOGRÁFICAS}

ANTOLIN, G.; TINAUT, F. V.; BRICENO, Y.; CASTANO, V.; PÉREZ, C.; RAMIREZ, A. I. Bioresource Technology 2002, 82 (2), 111.

ATKINS, P. W. Físico-Química. 6 ed., Rio de Janeiro: Livros Técnicos e Científicos, 1999.

BOTTON, V.; RIVA, D.; SIMIONATTO, E. L.; WIGGERS, V. R.; ENDER, L.; MEIER, H.F.; BARROS, A. A. C. Craqueamento termo-catalítico da mistura de óleo de fritura 
usado-lodo de estamparia têxtil para a produção de óleo com baixo índice de acidez. Química Nova, v. 35, n. 4, p. 677-682, 2012.

CHOE, E.; MIN, D. B. Chemistry of deep-fat frying oils. Journal of Food Science, v. 72, n. 5, p. 77-86, 2007.

COSTA NETO, P. R. da; FREITAS, R. J. S. de. Purificação de óleo de fritura. Boletim do CEPPA, v. 14, n. 2, p. 163-170, 1996.

COSTA NETO, P. R. da; ROSSI, L. F. S.; ZAGONEL, G. F.; RAMOS, L. P. Produção de biocombustivel alternativo ao óleo diesel através da transesterificação de óleo de soja usado em frituras. Química Nova, v. 23, n. 4, p. 531-537, 2000.

FERRARI, R. A. OLIVEIRA, V. da S., SCABIO, A. Biodiesel de Soja - Taxa de Conversão em Ésteres Etílicos, Caracterização Físico-Química e Consumo em Gerador de Energia. Química Nova, v.28, 2005.

FUKUDA, H.; KONDO, A.; NODA, H. J. Bioscience. Bioengeneering. 2001, 92 (5), 405.

LEITE, C. V. C. Produção de biodiesel usando misturas de óleos virgens e residuais: purificação com adsorventes. 2008. 126 f. Dissertação (Mestrado em Engenharia Mecânica) - Programa de Pós-Graduação em Engenharia Mecânica e de Materiais, Universidade Tecnológica Federal do Paraná, Curitiba, 2008.

McCABE, W. L.; SMITH, J. C.; HARRIOTT, P. Unit Operations of Chemical Engineering. 5 ed. Singapura: McGraw-Hill, 1993.

MEHER, L. C.; SAGAR, D. V.; NAIK, S. N. Technical aspects of biodiesel production by transesterification - a review. Renewable and Sustainable Energy Reviews, n.10, p. 248-268, 2006.

MELO, B. N. de. Compósitos obtidos a partir de matrizes poliuretônicas reforçadas com fibras de sisal, luffa e serragem modificadas. 172 f.Tese (Doutorado em Química) Departamento de Química, Universidade Federal de Minas Gerais, Belo Horizonte, 2008.

VARGAS, T. V. Tratamento do óleo de fritura utilizando fibra de coco para posterior aplicação na produção de biocombustiveis. Trabalho de Conclusão de Curso, Universidade Federal do Espirito Santo, 2013.

ZAMBELLI, R. A. Relatório referente a prática de determinação de acidez em óleos. Universidade Federal do Ceará, Fortaleza, 2009. Disponível em: $<$ http://www.ebah.com.br/content/ABAAAA7vsAA/acidez-oleos $>$. Acesso em: 01 de Março de 2015.

ZHANG, Y.; DUBÉ, M. A.; McLEAN, D. D.; KATES, M. Biodiesel production from waste cooking oil: Economic assessment and sensitivity analysis. Bioresource Technology, v. 90 , n. 3, p. 229-240, 2003. 